\title{
Studying micro dynamics in civil wars: introduction
}

\author{
Roos Haer · Johannes Vüllers • Nils B. Weidmann
}

Published online: 15 November 2019

(C) The Author(s) 2019

\begin{abstract}
This article introduces the special issue on the micro-level dynamics of civil wars. Until recently, most empirical work on these conflicts and their consequences has focused on the level of the sovereign state. In contrast, a micro-level approach is categorized by three distinct-albeit intertwined-features: a disaggregation by actors, time and space, interdisciplinarity, and the reliance on a set of different methods for the collection of data. The contributors to this special issue illustrate different approaches to the study of micro-level dynamics. The first part of the Special Issue provides new insights into the international level of civil war affects local conflict dynamics. The second part of the Special Issue is focused on the dynamics occurring at the group and the individual level. The diverse range of contributions to this Special Issue not only illustrate the scientific potential of the individual approaches to micro dynamics of armed conflict, but also the more general contributions that this kind of approach can offer to peace and conflict studies.
\end{abstract}

Keywords Micro-level analysis · Civil war · Disaggregation · Causal mechanisms $\cdot$ Micro-level data

R. Haer $(\bowtie) \cdot$ J. Vüllers

Leiden University, Leiden, The Netherlands

E-Mail: r.van.der.haer@fsw.leidenuniv.nl

J. Vüllers

E-Mail: j.vullers@fgga.leidenuniv.nl

N. B. Weidmann

University of Konstanz, Konstanz, Germany

E-Mail: nils.weidmann@uni-konstanz.de 


\section{Die Analyse von Mikro-Dynamiken in Bürgerkriegen: Einleitung}

Zusammenfassung Die meisten Studien haben bis vor kurzem noch Konflikte und ihre Konsequenzen auf der nationalen Ebene untersucht. Das Sonderheft umfasst hingegen theoriegeleitete empirische Studien, die sich explizit mit Dynamiken auf der Mikroebene auseinandersetzen. Der Mikroebenen-Ansatz zeichnet sich durch drei Merkmale aus: der Disaggregation von Akteuren, sowie von Daten auf der zeitlichen und räumlichen Ebene; einem interdisziplinären theoretischen Zugang; und der Verwendung unterschiedlicher Verfahren zur Datenerhebung. Die Studien in diesem Sonderheft zeigen in ihren Ansätzen die große Vielfalt in diesen drei Merkmalen auf. Der erste Teil umfasst Beiträge, die den Einfluss internationaler Akteure und der internationalen Ebene auf lokale Konfliktdynamiken untersuchen. Die Arbeiten im zweiten Teil untersuchen Dynamiken auf der Gruppen- und Individualebene. Die Beiträge im Sonderheft sind nicht nur repräsentativ für die verschiedenen Ansätze im Forschungsprogramm zu Mikro-Dynamiken in Bürgerkriegen, sie zeigen ferner auch das Potential von diesem Analyseansatz für die Friedens- und Konfliktforschung allgemein.

Schlüsselwörter Mikro-level Analyse $\cdot$ Bürgerkriege $\cdot$ Disaggregierung · kausale Mechanismen · Mikro-level Daten

Past and present violent conflicts, ranging from state wars, civil wars to riots and violent mass protests, affect the lives of millions of people every year across the world (Verwimp et al. 2009). They do not only hamper human and economic development but they also imperil the process of building democracy and establishing peaceful international orders and relations within and between states.

Until recently, most empirical studies examining these conflicts and their consequences have done so at a highly aggregated level. These so-called macro-level studies of armed conflict have examined processes of conflict and violence that take place at the level of the sovereign state (e.g., establishment of elections, restructuring of property rights, justice and security reforms, demobilization and reconstruction programs, peace agreements, conflict negotiations, and outcomes) (Balcells and Justino 2014). For instance, civil wars were often examined at the level of nation states, where states at large are coded to be either "at war" or not. Also, Collier and Hoeffler (2004) have looked at factors influencing the likelihood that a particular state will experience conflict rather than analyzing conflict at the level of regions within a country, the level of armed groups, or at the individual level.

Although these macro-level studies have pushed the field further by pointing towards potential new factors influencing the onset, duration and the consequences of armed conflicts, much is lost by this overly aggregated perspective. First, most of these macro-level studies pay insufficient consideration to the role of causal mechanism and micro-level foundations (i.e. Sambanis 2004; Kalyvas 2006; Kalyvas et al. 2008; Verwimp et al. 2009). They seem to ignore the fact that at a fundamental level, conflict originates from individuals' behavior and their repeated interactions 
with their surroundings, in other words, from its micro-foundations (Verwimp et al. 2009).

Second, there often seems to be a significant disconnect between macro-level perspectives on conflict, and the reality at the micro-level (i.e. Sambanis 2004). Kalyvas (2003), for example, reminds us that a perceived macro-level issue for conflict can significantly deviate from the actual motives for why people fight. Similarly, civil peace does not mean that conflict at the local level has ended.

In response to this criticism, a lively research field has emerged focusing on the micro-level of conflicts. This research field has raised new questions and generated insights that affect the wider field of peace and conflict research. For example, some scholars have focused on the "local turn" of peacebuilding to explain the failure of peace processes. Scholars working in this particular field have shown that the interaction between international peacekeepers and the local population is important for our understanding of the success or failure of peace processes (e.g., Autesserre 2014; Leonardsson and Rudd 2015; Paffenholz 2015). Recent studies on United Nations (UN) peacekeeping have followed a similar approach and improved our understanding on how the cultural distance between the "locals" and peacekeepers can contribute to the success or failure of international peacekeeping missions (e.g., Bove and Ruggeri 2019; Ruggeri et al. 2017). These approaches not only emphasize the importance of the actors at the local level, but also the relevance of investigating everyday activities rather than focusing on extraordinary activities such as riots or murders (e.g., Mac Ginty 2014; Autesserre 2014). The studies, therefore, provide new explanations for the spatial differences of violence in deeply divided societies (e.g., Dowd 2016).

Another important example of new insights generated by this micro-level focus can be found among those scholars examining local orders and governance systems in times of conflict and peace. In particular, the hybrid order literature has challenged the long-term focus on the state as the most relevant and powerful actor in (local) governance (e.g., Boege et al. 2009; Millar 2014; Staniland 2012). As part of this literature, the governance functions of various non-state actors and their importance for local conflict and peace processes has been highlighted, such as governance by rebels (e.g., Arjona et al. 2015; Arjona 2016; Huang 2016), traditional authorities (e.g., Mustasilta 2018) or religious groups (e.g., De Juan et al. 2015; Krause 2018). This research has then also improved our understanding of the complexity of (re-)negotiation processes and political hierarchies at the local level.

\section{Studying microdynamics of armed conflict}

Micro-level studies of armed conflict have generally focused on the comparative analysis of the foundations of conflict and other forms of political violence at the micro level (Balcells and Justino 2014). This program, also called the microdynamics of armed conflict, is very diverse-in terms of epistemology, the disaggregation of actors, time and space, and methodology. Fig. 1 shows the key features of the research program on the microdynamics of armed conflict. All three features are 
Fig. 1 The key features of the "microdynamics of armed conflict" research field

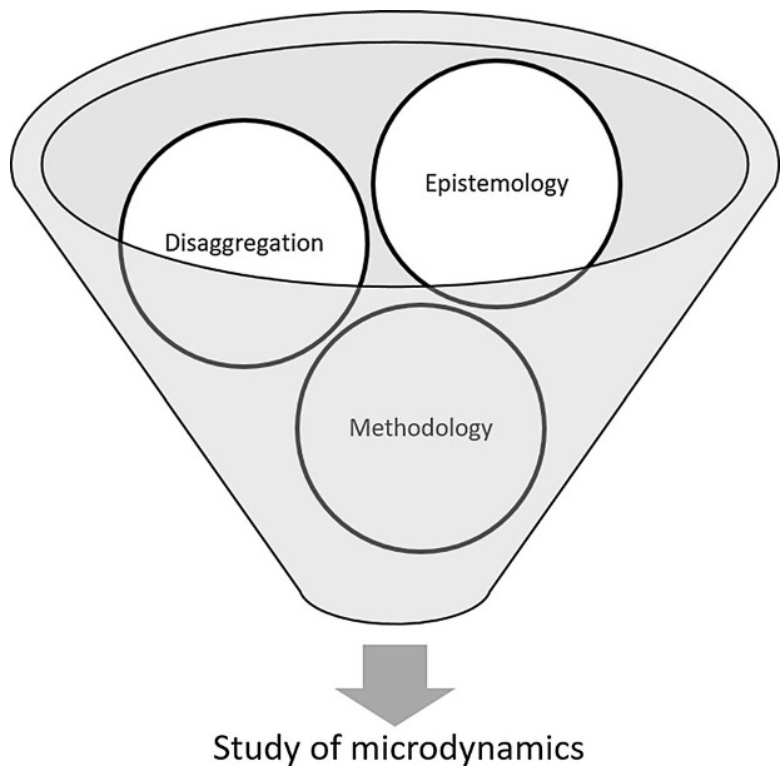

interlinked, but the epistemological approach provides the background for disaggregation and the required methodology for the data collection.

In political science, a distinction can be made between scientific empiricist approaches or hermeneutic approaches (Marsh and Furlong 2002). Subscribing to the scientific empiricist approach, most studies on the microdynamics of armed conflicts are interested in making causal statements for the detection and explanation of regularities of social phenomena. The approach of the research program can be described as theory-based empirical research.

Generally, the field is categorized by three distinct-albeit intertwined features. First, the field has overcome disciplinary boundaries because it focuses on explaining phenomena at the micro-level. While the first investigations in the field of internal conflict were based on classical theories of international relations (e.g., Fearon 1995; Lake 2003), the research program had to broaden its theoretical perspectives to explain dynamics at a lower level of analyses. Consequently, studies of the microdynamics of armed conflict often use theoretical approaches from different disciplines, such as psychology, criminology, sociology, history, computer science and economics. These disciplines provide a strong theoretical framework for translating macro-level theories to a lower level one and/or help us to analyze the necessary collected information. For instance, researchers use theoretical frameworks from sociology (outbidding, organizational competition) to explain the impact of competitive levels between groups on the extent of violence (e.g., Horowitz et al. 2018). Other studies use theories of criminology, sociology and psychology to explain the involvement of individuals in violent extremism and their withdrawal from such activities (e.g., Altier et al. 2014).

A second feature of the microdynamics research program is the disaggregation by actors, time and space, which is necessary if we want to capture causal processes 
at more fine-grained levels of analysis. For instance, the research program focuses on actors who feature less prominently in state-centric, macro-level research, such as individuals, households, rebel organizations, or particular population groups such as refugees or children. Moreover, these actors are often examined across time and space. For example, many micro-level conflict studies look at variation at the regional level (e.g., Østby 2008), variation in behavior of groups or individuals over time (e.g., Haer and Böhmelt 2016) and/or use precise event data to determine the specific conflict dynamics at the local level (e.g., Weidmann 2016).

Finally, the disaggregation of actors, time and space requires very fine-grained data to identify empirical patterns and to make reliable statements about the causal mechanisms or empirical patterns. The research program relies on a set of different methods to collect data, such as individual surveys, archival research, and Geographical Information Systems (GIS). The use of new data collection methods has led to an increase in new data sets in this field. These data sets include systematic information on topics that were only discussed anecdotally, if at all, in the literature a decade ago. For instance, Lyall et al. (2013) employs a survey experiment in Afghanistan to measure civilian attitudes toward combatants affected by wartime victimization. Others, such as Wig and Kromrey (2018), have systematically collected information on several features of customary institutions in sub-Saharan Africa, and have investigated whether these features matter for their involvement in communal-conflicts.

A potential disadvantage of these specific data collection efforts is that they generate disaggregated data for a specific case (for instance, when using archive sources) or at a specific time (for instance, surveys held at a specific time in a particular country), making generalizability problematic. In light of this problem, the $x S u b$ project was set up, which not only archives various micro-level data collection efforts but also allows for combining them into a common disaggregated data structure in terms of time and space (Zhukov et al. 2019). Notwithstanding, much more needs to be done in terms of coordination and transparency of micro-level data collections to ensure that resources are not reinvested in the repeated collection of the same information, and that the datasets use comparable levels of disaggregation.

\section{Challenges in the micro-level analysis of violent conflict}

The shift to a more micro-level perspective on armed conflict has given rise to a multitude of new insights and has resulted in a better understanding of the determinants and consequences of conflict. However, disaggregated micro-level analysis is not without problems. In the following, we highlight some of its challenges.

One important drawback of this disaggregation is of theoretical nature. If we assume an exclusively micro-level focus, we risk losing sight of the ways in which the dynamics of conflict observed at the local level may affect, but also are affected by, wider political, economic, or social processes (Balcells and Justino 2014). In contexts of armed conflict, for instance, we know that the way in which individuals, households, rebel groups react and adapt to violence depend also on issues and dynamics occurring at the macro-level. For instance, international support influences the behavior of rebel groups at the local level (Beber and Blattman 2013). 
Another more general issue in the micro-level analysis is the generalization of one's findings to other cases and contexts. While micro-level studies can provide us with detailed insights on the particular case we have examined, it is often difficult to tell whether these insights can also be applied elsewhere. Here, we encounter a fundamental challenge in the social science, which is the tension between rich and detailed case analyses (which is typically what the micro-level research program does) and broad comparative analyses with many cases, but usually only a superficial treatment of each of them. In this sense, the micro-level analysis of armed conflict constitutes one in the range of different social science research approaches, each of which has particular strengths and weaknesses.

Finally, we have already discussed the variety of sources for empirical data that can be used in micro-level research, and particular challenges can arise in the data collection process. Disaggregated studies have high demands when it comes to the quality and the resolution of the data they use. For example, event-based analyses of civil war (such as Weidmann 2011) require many details about individual confrontations between the fighting parties, including where the event occurred, when it happened, as well as who participated. Oftentimes, this information is not collected systematically during a conflict, but needs to be compiled by the researchers themselves on the basis of secondary sources, such as newspapers. This entails many questions about completeness, bias and accuracy of the information reported (Weidmann 2015, 2016). In general, depending on the used sources used for the collection of micro-level data, researchers need to be aware of the limitations affecting them.

\section{Overview of the special issue}

In this Special Issue, we make a renewed effort to put micro-level conflict dynamics and their consequences at the center of the analysis. We have brought together a group of authors that use different theories to explain particular micro-level conflict-related phenomena. In doing so, they leverage a great variety of methodological approaches and levels of analysis: they disaggregate by actor, time and space. We show that micro-level approaches can generate important theoretical and empirical insights into the dynamics of conflict, by their ability to account for variation at different levels of analysis.

This Special Issue consists of two parts. The first part focuses on the impact of macro level processes on micro level dynamics. In doing so, we attempt to fill an important theoretical shortcoming of the field, which has overlooked the interaction between both levels. Papers in this section provide new insights into different aspects related to the involvement of international actors, or the international level on local conflict dynamics.

Peitz and Reisch study the impact of international troops on local conflict dynamics. To investigate the territorial impact of the presence of peacekeepers, they collected spatially disaggregated data on the presence of United Nations peacekeepers in the Democratic Republic of the Congo. Their findings show that the presence of UN peacekeepers reduces the level of violence in the locality, but the presence of the peacekeepers leads to a spatial diffusion of the fighting places. 
Disaggregating the conflict actors, Sienknecht's paper investigates which strategies rebel groups employ to gain recognition from international actors. The study presents new data based on newspapers and documents from international organizations. It shows that in about $60 \%$ of all cases, rebel groups actively demand to be recognized by international actors.

The paper by Krauser et al. focuses on examining the impact of international investment in the oil sector on female employment, and how this might foster grievances. To do this, the authors examine its effect on the household level using survey data from Africa. They note that the extractive industry only marginally increases the gender gap in the labor market and does not increase the violence in the personal relations.

Articles in the second section of this Special Issue focus on the group and individual level. Krtsch and Vüllers analyze the impact of the implementation of peace agreements on civilian activism. They use existing data sets, but disaggregate that data by actor, time, and spatial level. Their study shows that the implementation of power-sharing provisions in peace agreements triggers protests and unrest among various ethnic groups in the country.

Lastly, Bohnet and Rüegger present a new dataset and empirical insights of violent incidents involving refugees in Central and East Africa. The Refugee-Related Security Incidence Dataset (RRSID) is a novel dataset that disaggregates the actors and spatial levels. RRSID distinguishes between different types of violence against refugees and shows that sexual and gender-based violence is more common than violence involving rebel groups.

The diverse range of contributions to this Special Issue not only represent the different approaches and variations of the research program on micro dynamics of armed conflict, but also show the very fruitful contributions that this kind of approach can offer to conflict and peace studies. The first part of this special issue shows that there is significant interaction between the international and lower levels of analyses. The contributions do not only show that the international level (operationalized as international investment, UN peacekeeping) influences the local level, but also the other way around. Rebel groups, for instance, look at the international order and adapt their strategies in order to gain recognition. This "game" between the different levels has noteworthy consequences for conflict and conflict-affected actors. For instance, our contributions show that it can reduce violence and that it does not increase interpersonal violence. The second part of this special issue looks in particular at how lower-level actors are affected by conflict. This part shows us two important things. First, new data collection efforts, such as the RRSID dataset can generate new insights, which stand in sharp contrast to common knowledge. Second, empirical micro-level research can also reject common held assumptions, such as the implementation of power-sharing provisions stabilizes peace.

All in all, this special issue does not only uncover the link between macro and micro but also widens our perspective to include actors and factors that were previously overlooked. 
Open Access This article is distributed under the terms of the Creative Commons Attribution 4.0 International License (http://creativecommons.org/licenses/by/4.0/), which permits unrestricted use, distribution, and reproduction in any medium, provided you give appropriate credit to the original author(s) and the source, provide a link to the Creative Commons license, and indicate if changes were made.

\section{References}

Altier, Mary B., Christian N. Thoroughgood, and John G. Horgan. 2014. Turning away from terrorism: lessons from psychology, sociology, and criminology. Journal of Peace Research 51(5):647-661.

Arjona, Anna. 2016. Rebelocracy: social order in the Colombian civil war. New York: Cambridge University Press.

Arjona, Anna, Nelson Kasfir, and Zachariah Mampilly (eds.). 2015. Rebel governance in civil war. New York: Cambridge University Press.

Autesserre, Séverine. 2014. Peaceland: conflict resolution and the everyday politics of international intervention. New York: Cambridge University Press.

Balcells, Laia, and Patricia Justino. 2014. Bridging micro and macro approaches on civil wars and political violence: issues, challenges, and the way forward. Journal of Conflict Resolution 58(8):1343-1359.

Beber, Bernd, and Christopher Blattman. 2013. The logic of child soldiering and coercion. International Organization 67(1):65-104.

Boege, Volker, Anne Brown, Kevin Clements, and Anna Nolan. 2009. Building peace and political community in hybrid political orders. International Peacekeeping 16(5):599-615.

Bove, Vincenzo, and Andrea Ruggeri. 2019. Peacekeeping effectiveness and blue helmets' distance from locals. Journal of Conflict Resolution https://doi.org/10.1177/0022002719826115.

Collier, Paul, and Anke Hoeffler. 2004. Greed and grievance in civil war. Oxford Economic Papers 56(4):563-595.

De Juan, Alexander, Jan H. Pierskalla, and Johannes Vüllers. 2015. The pacifying effects of local religious institutions: an analysis of communal violence in Indonesia. Political Research Quarterly 68(2):211-224.

Dowd, Robert A. 2016. Religious Diversity and Religious Tollerance: Lessons from Nigeria. Journal of Conflict Resolution 60(4):617-644.

Fearon, James. 1995. Rationalist explanations for war. International Organization 49(3):379-414.

Ginty, Mac Roger. 2014. Everyday peace: bottom-up and local agency in conflict-affected societies. Security Dialogue 45(6):548-564.

Haer, Roos, and Tobias Böhmelt. 2016. Child soldiers as time bombs? Adolescents' participation in rebel groups and the recurrence of armed conflict. European Journal of International Relations 22(2):408-436.

Horowitz, Michael, Evan Perkoski, and Philip Potter. 2018. Tactical diversity and militant violence. International Organization 72(1):139-171.

Huang, Reyko. 2016. The wartime origins of democratization: civil war, rebel governance and political regimes. New York: Cambridge University Press.

Kalyvas, Stathis N. 2003. The ontology of "political violence": action and identity in civil wars. Perspectives on Politics 1(3):475-494.

Kalyvas, Stathis N. 2006. The logic of violence in civil war. Cambridge: Cambridge University Press.

Kalyvas, Stathis N., Ian Shapiro, and Tarek Masoud (eds.). 2008. Order, conflict, and violence. Cambridge: Cambridge University Press.

Krause, Jana. 2018. Resilient communities: non-violence and civilian agency in communal war. New York: Cambridge University Press.

Lake, David. 2003. International relations theory and internal conflict: insights from the interstices. International Studies Review 5(4):81-89.

Leonardsson, Hanna, and Gustav Rudd. 2015. The "local turn" in Peacebuilding: a literature review of effective and Emancipatory local Peacebuilding. Third World Quarterly 36(5):825-839.

Lyall, Jason, Graeme Blair, and Kosuke Imai. 2013. Explaining support for combatants in wartime: a survey experiment in Afghanistan. American Political Science Review 107(4):679-705.

Marsh, David, and Paul Furlong. 2002. A skin not a sweater: ontology and epistemology in political science. In Theories and methods in political science, ed. David Marsh, Gerry Stocker, 177-198. New York: Palgrave Macmillan.

Millar, Gearoid. 2014. Disaggregating Hybridity: why hybrid institutions do not produce predictable experiences of peace. Journal of Peace Research 51(4):501-514. 
Mustasilta, Katariina. 2018. Including chiefs, maintaining peace? Examining the effects of state-traditional governance interaction on civil peace in sub-saharan africa. Journal of Peace Research 56(2):203-219.

Østby, Gudrun. 2008. Polarization, horizontal inequalities and violent civil conflict. Journal of Peace Research 45(2): 143-162.

Paffenholz, Thania. 2015. Unpacking the local turn in Peacebuilding: a critical assessment towards an agenda for future research. Third World Quarterly 36(5):857-874.

Ruggeri, Andrea, Han Dorussen, and Theodora-Ismene Gizelis. 2017. Winning the peace locally: UN peacekeeping and local conflict. International Organization 71(1):163-185.

Sambanis, Nicholas. 2004. Using case studies to expand economic models of civil war. Perspectives on Politics 2(2):259-179.

Staniland, Paul. 2012. States, insurgents, and wartime political order. Perspectives on Politics 10(2):243-264.

Verwimp, Philip, Patricia Justino, and Tilman Brück. 2009. The analysis of conflict: a micro-level perspective. Journal of Peace Research 46(3):307-314.

Weidmann, Nils B. 2011. Violence "from above" or "from below"? The role of ethnicity in Bosnia's civil war. Journal of Politics 73(4):1178-1190.

Weidmann, Nils B. 2015. On the accuracy of media-based conflict event data. Journal of Conflict Resolution 59(6):1129-1149.

Weidmann, Nils B. 2016. A closer look at reporting bias in conflict event data. American Journal of Political Science 60(1):206-218.

Wig, Tore, and Daniela Kromrey. 2018. Which groups fight? Customary institutions and communal conflicts in africa. Journal of Peace Research 55(4):415-429.

Zhukov, Yuri M., Christian Davenport, and Nadiya Kostyuk. 2019. Introducing xsub: a new portal for cross-national data on Subnational violence. Journal of Peace Research https://doi.org/10.1177/ 0022343319836697. 